\title{
One-step Synthesis of Anisotropic Gold Nanoparticles with the Extract from Wuluh Starfruit (Averrhoa bilimbi) as Reducing and Morphology Controlling Agent
}

\author{
FOLIATINI ${ }^{1}$ and NURDIANI ${ }^{2}$ \\ ${ }^{1}$ Chemical Analysis Department, Polytechnic of AKA Bogor, Bogor-16154, Indonesia. \\ ${ }^{2}$ Departement of Industrial Waste Treatment Polytechnic of AKA Bogor, Bogor-16154, Indonesia. \\ ${ }^{*}$ Corresponding author E-mail: nurdiani97@gmail.com \\ http://dx.doi.org/10.13005/ojc/350429
}

(Received: June 22, 2019; Accepted: August 20, 2019)

\begin{abstract}
The synthesis of anisotropic gold nanoparticles have been successfully conducted using one-step experimental procedures, with the aid of extract from wuluh starfruit (Averrhoa bilimbi) as reducing agent. The synthesis was carried out in the microwave oven at certain power of irradiation. The as-formed nanoparticles were characterized by UV-Vis spectrophotometry and transmission electron microscopy (TEM). The phytochemical assay and ascorbic acid determination was done to support the prediction about the contribution of those compounds in the synthesis. The antimicrobial activity was assayed toward some bacteria. The results confirmed that the amount of phytochemicals and ascorbic acid in the extracts may contribute largely to the effectivity of the synthesis. The morphology of these nanoparticles was greatly affected by both the gold precursor concentration and volume ratio of precursor : extract. The as-formed nanoparticles have medium antibacterial activity, toward Escherichia coli and Bacillus, in which the magnitude of antibacterial activity depends on the ratio of precursor : extract.
\end{abstract}

Keyword: Gold nanoparticles, Wuluh starfruit (Averrhoa bilimbi), Morphology, Antibacterial, Surface plasmon resonance spectra.

\section{INTRODUCTION}

Metal nanoparticles exhibit superior properties like optical, mechanical, and chemical reactivity, hence they could be potential in many fields, including pharmacy, biology, medical, agricultural, physics and environment. Many reports prove that gold and silver nanoparticles have a bactericidal effect on a range of microorganisms and their bactericidal effects depend on the size and shape of the particle. Nanoparticles can act as antibacterial and antifungal agents, due to their ability to interact with microorganism ${ }^{1}$. Since the morphology can be controlled by the synthesis process, thus, the selection of the preparation method for synthesizing nanoparticles must be carefully considered.

The green method of nanoparticle synthesis employing extract of part of plants is simple and viable alternative to chemical and physical techniques ${ }^{2}$. The main advantage of the green synthesis is the absenie

This is an Open Access article licensed under a Creative Commons license: Attribution 4.0 International (CC- BY). Published by Oriental Scientific Publishing Company @ 2018

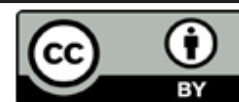


of harmful chemicals thus do not make a negative impact to the environment. For this reason, in recent years, biosynthesis of nanoparticles has received considerable attention ${ }^{3}$.

The process of reducing metal precursors in the synthesis of metal nanoparticles involving biomolecule compounds extracted from parts (roots, stems, leaves) of plants, is growing rapidly in this decade, due to the effectiveness of high synthesis and nontoxic product properties. These biomolecular compounds generally have bulky groups, so that they can simultaneously act as stabilizers for the metal nanoparticles produced. Various types of plant extracts have been used for this purpose, for example Tamarind leaf extract ${ }^{4}$, Azadirachta indica (Neem) leaf extract ${ }^{4}$, geranium leaf extract ${ }^{5}$, and Amaranthus spinosus leaf extract ${ }^{6}$, black cardamom extract $^{7}$, Melia azedarach bark extract ${ }^{8}$, binahong (Anredera cordifolia) leaves extract ${ }^{9}$. Wuluh starfruit is a plant that is often found in Indonesia and is often used as a medicine. The research showed abundant flavonoid content in the wuluh starfruit, so that the wuluh starfruit was potential to be used as a reducing agent in the synthesis of Au nanoparticles ${ }^{10}$. In addition to particle size, particle shape is a factor that influences the characteristics of metal nanoparticles, and several studies show that shapes other than spheres (for example stems) have higher activity as sensors and in the biomedical field. Gold nanoparticles having shape of rod, triangular prisms, cubes and hollow cubes also absorb radiation from the near infrared region intensively so that it can be utilized in photothermal therapy to destroy cancer cells ${ }^{11}$. Firdhouse and Lalitha ${ }^{12}$ reported that flower shaped gold nanoparticles synthesizaction using Kedrostis foetidissima have antiproliferative against bone cancer cell lines.

Various techniques have been explored to be able to synthesize Au nanoparticles with unsymmetrical shapes. One of the techniques that has been studied includes bottom up by selecting the type of reducing agent, controlling the $\mathrm{pH}$, temperature, the ratio of the concentration of metal precursors: reducing, ionic strength, etc. ${ }^{13,14}$. In this study several variations of experimental conditions were carried out to obtain optimum conditions in the synthesis of $\mathrm{Au}$ nanoparticles with shapes other than spherical.

\section{EXPERIMENTAL}

\section{Materials}

$\mathrm{HAuCl}_{4}$ was prepared from $\mathrm{Au}$ metal (99, 99\%, gold purchased from PT. Antam, Tbk) by dissolving the metal in aquaregia, and vaporized until the volume was only one third, diluted to initial volume and repeated the vaporization-dilution process three times to remove any impurities. Wuluh starfruits (Averrhoa bilimbi) were bought from local market in Bogor, Indonesia. Double distilled water was used throughout this experiment. The picture of Wuluh starfruit can be seen more clearly in Figure 1 below.

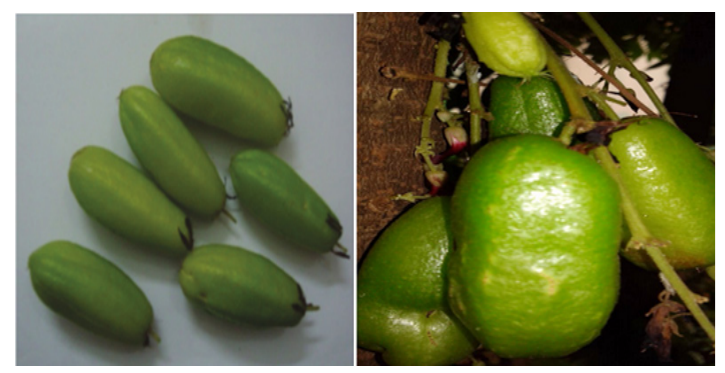

Fig. 1. Wuluh starfruit from local market in Bogor, Indonesia

\section{Experiment}

This study includes several stages, namely the synthesis and characterization of Au nanoparticles, and testing of antibacterial properties. Synthesis of Au nanoparticles was carried out by a bottom-up technique using the wuluh starfruit (Averrhoa bilimbl) as a reducing agent and stabilizer, and with the aid of microwave irradiation. $50 \mathrm{~g}$ of fresh wuluh starfruit samples were cut into pieces and then boiled in hotplate $\left(20 \mathrm{~min} 70^{\circ} \mathrm{C}\right)$ with $100 \mathrm{~mL}$ of double-distilled water. The water extract obtained is then filtered and $50 \mathrm{~mL}$ of water filtrate was analyzed for its content by phytochemical test. The extract was then used to synthesize Au nanoparticles.

Synthesis of $\mathrm{Au}$ nanoparticles was carried out with the aid of microwaves at certain regulated power. As much as a certain volume of $0.5 \mathrm{mM} \mathrm{HAuCl}_{4}$ solution is put into a beaker glass then extracts are added with a certain volume until the total volume is $20 \mathrm{~mL}$. Beaker was into a microwave oven then warm up for 2-3 minutes. The color change from clear yellow to red or purple indicates that $\mathrm{Au}$ nanoparticles have been formed. The formed Au nanoparticle colloids were centrifuged at $3000 \mathrm{rpm}$ for $30 \mathrm{~min}$ and ready to be characterized. Antibacterial samples of the $A u$ nanoparticles were also tested for their antibacterial 
properties by measuring the antibacterial pathogen nanoparticles (modified method from ${ }^{13}$ ) with the following procedure: E. coli bacteria, staphylococcus aureus, Pseudomonas aeruginosa, cultured in agar (Lysogeny Broth/Lactose Broth) LB media for one night, then placed in a sterile cup containing nano $\mathrm{Au}$ and some standards of penicillin antibiotics. The development of bacteria around the cup paper was observed. Medium LB or Lysogeny Broth/Lactose Broth is a rich medium that can be used to grow various types of bacteria, but is widely used to grow Escherichia coli bacteria, especially for the purposes of genetic analysis and engineering involving the Gram-negative bacteria.

\section{Characterization}

UV-Visible Spectrophotometer (UV-1700, Shimadzu) was used to characterize SPR spectra of the Au nanoparticles, Fourier-Transform Infra Red spectrometer (Bruker) was employed to identify the functional groups in the system of extract-capped Au nanoparticles, Transmission Electron Microscopy (JEM-1400, JEOL) was used to characterize the morphology of the particles, especially the particle size and shape and its distribution.

\section{RESULTS AND DISCUSSION}

"Belimbing wuluh"/ wuluh starfruit (Averrhoa bilimbi) was selected as reducing agent and stabilizer in this Au nanoparticles synthesis since this wuluh starfruit contains large amount of phytochemicals ${ }^{14}$, that may have reducing capacity and bulky structure which is required in the stabilization process of particles. Several studies proves that these phytochemicals were able to reduce metal precursors to some extent ${ }^{16}$ but rarely discuss about the selection of extraction method of these substances, which is a crucial steps in obtaining suitable chemical composition in the reducing and stabilizing process. Extraction of phytochemicals in the starfruits was conducted using simple, low cost and environmentally friendly technique. The extraction involved boiling the thinly sliced-or pounded fruit using water as solvent and extracting agent at certain temperature. No other chemicals used in the extraction process. This boiling process can be repeated several times to evaluate the stability of the phytochemicals and the change in reducing and stabilizing capability of these substances. The influence of the technique employed in the synthesis was also evaluated in term of morphological particles and their stability.

\section{Replication Number of Boiling Process}

The experiment revealed that starfruit extract from first, second and third boiling step have successfully reduced the Au precursor, yielding the Au nanoparticles with various color of coloidal solution, as the concentration of Au precursor was varied.The trend of this change of colloid color was almost similar for three variation in replication number of boiling process. Extract of first, second and third boiling yielded $\mathrm{Au}$ nanoparticles at concentration of Au precursor $\geq 0.4 \mathrm{mM}$, except for third boiling which produced Au nanoparticles at Au precursor of $0.2 \mathrm{mM}$. At lower concentration, there was no significant change in color, indicating unsuccessful synthesis of Au nanoparticles. As the Au precursor concentration was increased, the color of colloidal solution change from magenta to dark magenta/ purple to blue, though the actual concentration may vary with different extract (Fig. 1). For extract from first and second boiling, the magenta colloidal solution were obtained at Au precursor concentration of $0.4 \mathrm{mM}$, while for extract from third boiling the same color was obtained at Au precursor concentration of $0.2 \mathrm{mM}$. The dark magenta solution could be produced at $\mathrm{Au}$ precursor concentration of $0.6 \mathrm{mM}$ for extract from first and second boiling, and the purple solution was yielded at Au precursor concentration of $0.4 \mathrm{mM}$ for extract from third boiling. The blue colloidal solution were obtained at Au precursor concentration $\geq 0.8 \mathrm{mM}$ for extract from first and second boiling and $\geq 0.6 \mathrm{mM}$ for extract from third boiling.

Previous study have been conducted using binahong (Anredera cordifolia) leaves for Au nanoparicles synthesis, in which replication number of boiling give no significant change of solution color of nanoparticles, but a slight wavelength shift in the UV-Vis spectrum, especially at high concentration of Au precursor ${ }^{9}$. Since in this research, the color of the colloidal solution was significantly changed, thus it should be considered as such a phenomenon of reaction effectivity and morphological alteration, which related to the amount of reducing agent from the extract. So far, the study about the effect of the extract preparation in the synthesis of metal nanoparticles was rarely, thus we are interested to explore it in this research. 
Based on this result, extract from third boiling need lower Au precursor concentration to produce nanoparticles, both magenta/purple and blue colloidal solution, indicated that it may have higher capacity in reducing Au precursor. The replication number of boiling process may relate to the effectivity of extraction process. There are two possibilities for the higher number of replication boiling, first, the more active substances are extracted, thus the more likely the nanoparticles formed, sec. the more likely the active substances to be degraded, especially for the substances with low thermal stability.

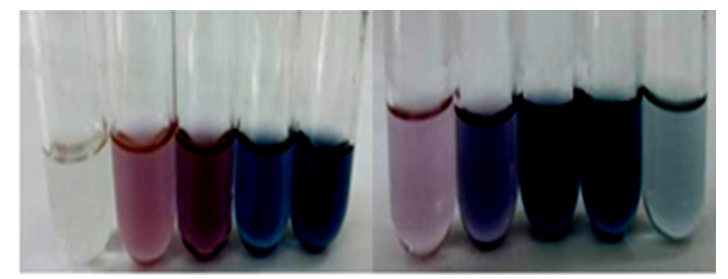

Fig. 2. Appearance of Au nanoparticle colloid using extract from the sec. boiling(left) and third boiling (right). Au precursor concentration $=0.2,0.4,0.6,0.8,1.0 \mathrm{mM}$ from left to right in each pictures

Nonspherical particles usually obtained in the condition such as low amount of reducing agent which leading to the low nucleation rate, and low amount of capping agent which resulting in the uncontrolled growth of particle in certain orientation. The results suggested that the composition and/or concentration of active substances in the extract from third boiling were changed due to the degradation of several substances. In order to prove the prediction, the extracts must be subjected to phytochemical assay.

Table 1: Phytochemical assay results for wuluh starfruit (Averrhoa bilimbi)

\begin{tabular}{lcccc}
\hline Extracts & $\begin{array}{c}\text { First } \\
\text { boiling }\end{array}$ & $\begin{array}{c}\text { Second } \\
\text { boiling }\end{array}$ & $\begin{array}{c}\text { Third } \\
\text { boiling }\end{array}$ & Chop \\
\hline Alkaloid : & & & & \\
- Dragendorff & ++ & + & + & + \\
- Meyer & +++ & ++++ & ++ & ++ \\
- Wagner & - & - & - & - \\
Tannin & - & - & - & - \\
Fenol & - & - & - & - \\
Saponin & +++ & ++ & + & ++ \\
Flavonoid & - & - & - & - \\
Terpenoid & +++ & + & - & + \\
Unsaturated steroids & - & - & - & - \\
Glycoside steroid & - & - & - & - \\
\hline
\end{tabular}

The phytochemical assay proved that the extract of wuluh starfruit contains alkaloids, saponins, and terpenoids, and the concentration of these substances may different for different replication number of boiling (Table 1). Another study reported that wuluh starfruit have flavonoid and terpenoid contents ${ }^{17}$. Alkaloids, saponins and terpenoid have been proved to play a significant role as reducing agent for several cationic metals ${ }^{17}$, thus in this experiment these bioactive substances have great importance in the synthesis of Au nanoparticles.

The saponins and terpenoids decreases when the replication number of boiling increases. The result explains the formation of nonspherical particles at low concentration of reducing agent, if it is assumed that these phytochemical substances really have large contribution in the synthesis as reducing agent. However, previous study reported that it was ascorbic acid in the wuluh starfruit which played a role as reducing agent ${ }^{2}$. Thus, we examined the probability of ascorbic acid to act as reducing agent, and compared the result for different replication number of boiling.

Table 2: Ascorbic acid determination by iodometric titration method

\begin{tabular}{lcccc}
\hline $\begin{array}{l}\text { Sample } \\
\text { Name }\end{array}$ & $\begin{array}{c}\text { Sample } \\
\text { Weight }(\mathrm{g})\end{array}$ & $\mathrm{I}_{2}(\mathrm{~mL})$ & Discoloration & $\begin{array}{c}\% \text { Ascorbic Acid } \\
\left(\%(\mathrm{~b} / \mathrm{b}) \times 10^{-2}\right)\end{array}$ \\
\hline Boiling 1 & 10.0113 & 0.2 & Brown $\rightarrow$ Blue & 3.57 \\
Boiling 2 & 10.0136 & 0.15 & & 2.68 \\
Boiling 3 & 10.0261 & 0.1 & & 1.78 \\
\hline
\end{tabular}

Table 2 confirmed that the higher replication number of boiling resulted lower concentration of ascorbic acid. This result supported the probability above about the capability of ascorbic acid in the reducing process of Au precursor. The concentration of ascorbic acid linearly decreases as the replication number of boiling increases. Fig. 2 revealed that when using extract from third boiling, it was more likely to get blue nanoparticles colloidal solution at lower concentration compared to another extract. Since the characteristic color of Au nanoparticles colloid related to formation of nonspherical particles, thus low content of ascorbic acid may lead to the formation of such those particles. When the ascorbic acid concentration was low, while maintaining the constant $\mathrm{Au}$ precursor concentration, the concentration ratio between reducing agent to $\mathrm{Au}$ precursor was also low. By considering data from Table 1 and Table 2, it can be predicted that both ascorbic acid and several phytochemicals may contribute as reducing and/or stabilizing agent in the synthesis of Au nanoparticles. 
Surface plasmon resonance spectra of the nanoparticles synthesized by extract from first, second and third boiling revealed similar trend, in which the higher the concentration of gold precursor, the higher the absorbance, and the broader the spectrum in the range of near infrared (Fig. 3). This phenomenon indicated that the probability of formation of large and/or nonspherical particles were higher. The fluctuation of absorbance in the peak of particles from sec. boiling related to the formation of

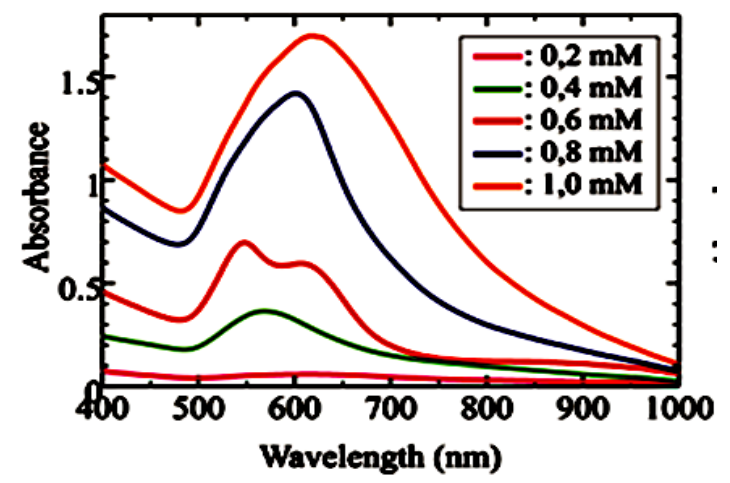

(a)

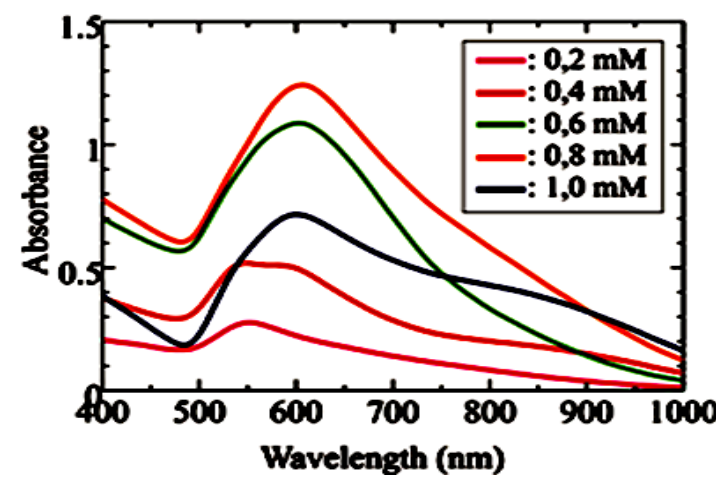

(c) a clear two overlapped peaks at Au concentration of $0.60 \mathrm{mM}$. In the synthesis using extract from third boiling, the absorbance was dropped when the Au precursor was increased to $1.0 \mathrm{mM}$. Since the extract from third boiling have low concentration of reducing agent, thus at high concentration of Au precursor, the amount of reducing agent were not sufficient for reduction process, resulting in low concentration of nanoparticles.

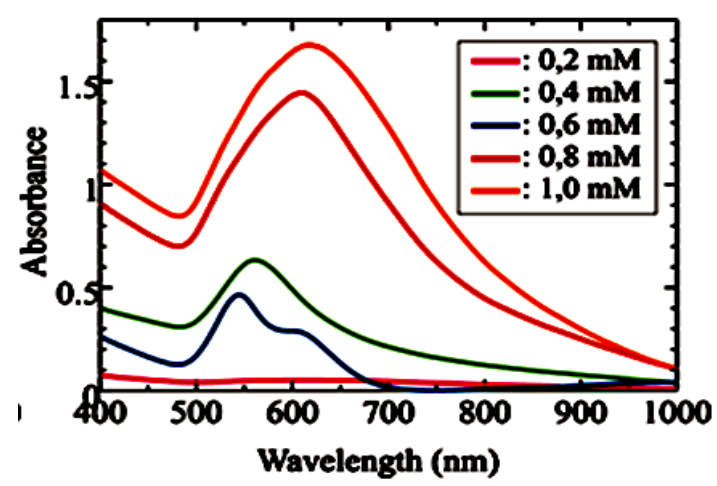

(b)

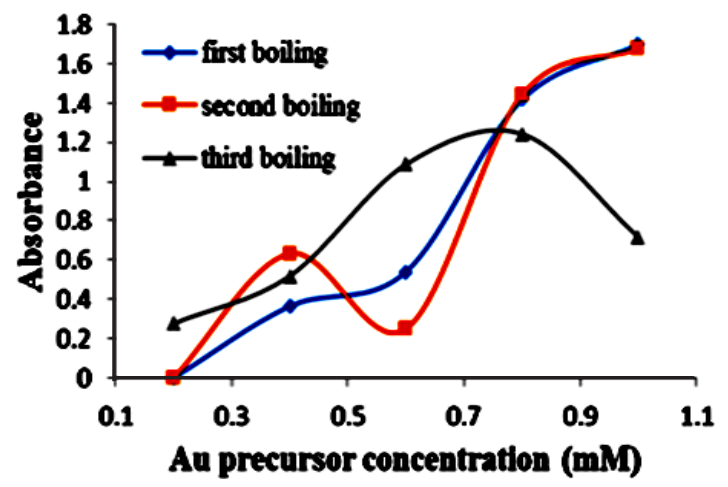

(d)

Fig. 3. SPR spectra of Au nanoparticles synthesized by wuluh starfruit extract from first (a), second (b) and third boiling (c), and the relation between absorbance and Au precursor concentration (d)

\section{Synthesis Techniques}

Several studies have been reported that the synthesis techniques played significant role on the morphology and optical properties of the as-obtained nanoparticles ${ }^{18}$. Different technique may use different intensity and frequency of energy, resulting different nucleation and growth rate of nanoparticles, thus may produce different nanoparticle size and shape.

In this experiment, the synthesis conducted by the heating and stirring process using hotplate was compared to that using microwave technique.
Previous studies proved that microwave technique resulted in the more homogeneous particle size ${ }^{19}$.

Figure 4 (left) showed that at low metal precursor concentration, the peak was actually consisted of two peaks, indicated that large and/or nonspherical particles was more probably formed. At higher concentration, similar trend was found, except in the sec. peak in near infrared region, which were less developed, and only seen as shoulder. Moreover, the first peak also red-shifted to higher wavelength. 

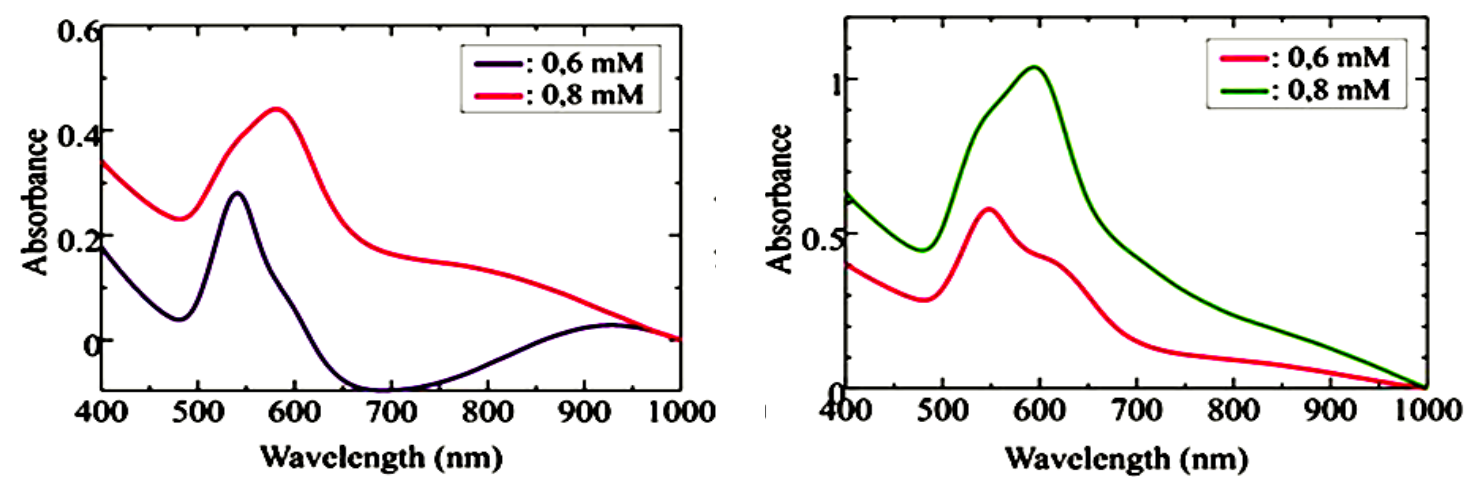

Fig. 4. SPR spectra of Au nanoparticles synthesized by bilimbi fruit extract at metal precursor concentration of $0.6 \mathrm{mM}$ and $0.8 \mathrm{mM}$, by conventional synthesis (boiling using hotplate) (left) and by microwave (right)

Synthesis technique using microwave irradiation at same precursor concentration and same volume ratio of precursor : extract, did not yield significant second peak in the near infrared region (800 - $1000 \mathrm{~nm}$ ), as shown in Fig. 4 (right). This indicated that the smaller and/or spherical Au nanoparticles were more commonly formed. Although these synthesis were conducted at similar temperature, the source of energy were different. Microwave oven emitted electromagnetic radiation which were selectively absorbed by ionic and/or polar species in the solution, created specific heating region in the reactant system ${ }^{20}$. The heating process does not depend on the thermal conductivity of the vessel. Gradient temperature are not found in the microwave synthesis, resulting more homogeneous nucleation rate in the formation of particles.

The effective radiation emitted by microwave oven also yielded larger number of particles, as shown by the higher absorbance in the SPR spectra. Actually, the overlapped peaks were also found in the spectra of Au nanoparticles synthesized by microwave heating, but the wavelength difference were not too high. These two peaks found in the spectra may come from the nonspherical particles.

\section{Effect of Volume Ratio of Metal Precursor : Extract}

Several studies reported in the previous references stated that the concentration ratio of metal precursor : reducing agent greatly influences both the optical and morphological characteristics of the as-obtained particles ${ }^{21}$. Since the wuluh starfruit extract played a role as both reducing agent and stabilizer in this synthesis, the higher concentration ratio of metal precursor : extract, the lower the amount of extract which are available to convert the metal precursor to zero valent species, and stabilized the as-formed nanoparticles. This condition decreased the nucleation rate and gave more chance to the inhomogeneous growth rate, leading to the formation of larger and/or nonspherical particles.

This phenomenon can be visually observed from the color formation of the Au nanoparticles at various metal precursor concentration and volume ratio of metal precursor : extract (Fig. 4). The blue color of colloidal solution were more likely to be formed at relatively higher ratio of volume ratio of metal precursor : extract, and at high concentration of Au precursor.

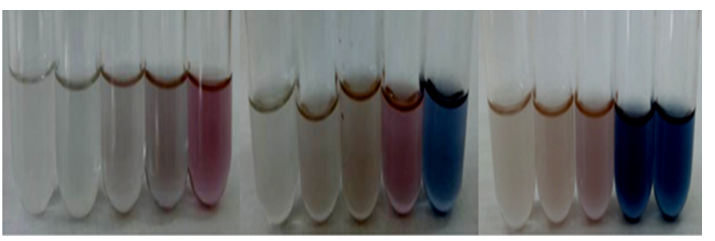

Fig. 5. Colloidal solution of Au nanoparticles at ratio volume of metal precursor : Extract of $6: 14,8: 12,10: 10$, $12: 8$ and $14: 6$ at metal precursor concentration of $0.4 \mathrm{mM}$ (left), $0.6 \mathrm{mM}$ (middle), and $0.8 \mathrm{mM}$ (right)

SPR spectra of Au nanoparticles at various volume ratio (Fig. 5) of metal precursor : extract showed that the characteristic peak of Au nanoparticles only formed at ratio of $10: 10$ and $12: 8$, at low concentration of metal precursor $(0.40 \mathrm{mM})$. At lower and higher ratio than those, the formation of peak were not significant. However, as the time went on, the formation of the peak were occurred, resulting even a higher peak than at ratio of $10: 10$ and $12: 8$.

Figure 5 also confirmed that the probability of formation of the nanoparticles were influenced by 
volume ratio of metal precursor : extract. At metal precursor concentration of $0.4 \mathrm{mM}$, the well-defined peaks were only emerged at volume ratio of $10: 10$ and $12: 8$. At lower volume ratio they were observed as shoulder or very broad peak at high wavelength. At volume ratio of $14: 6$, the peak was still not yet formed, but after 7 days after preparation, narrow, high absorbance-peak was found at this condition. These peaks also confirmed the formation rate of the synthesis which were very slow due to the low concentration of the metal precursor.

The change of absorbance as the volume ratio of of metal precursor : extract increases, were shown at Fig. 7. At metal precursor concentration of
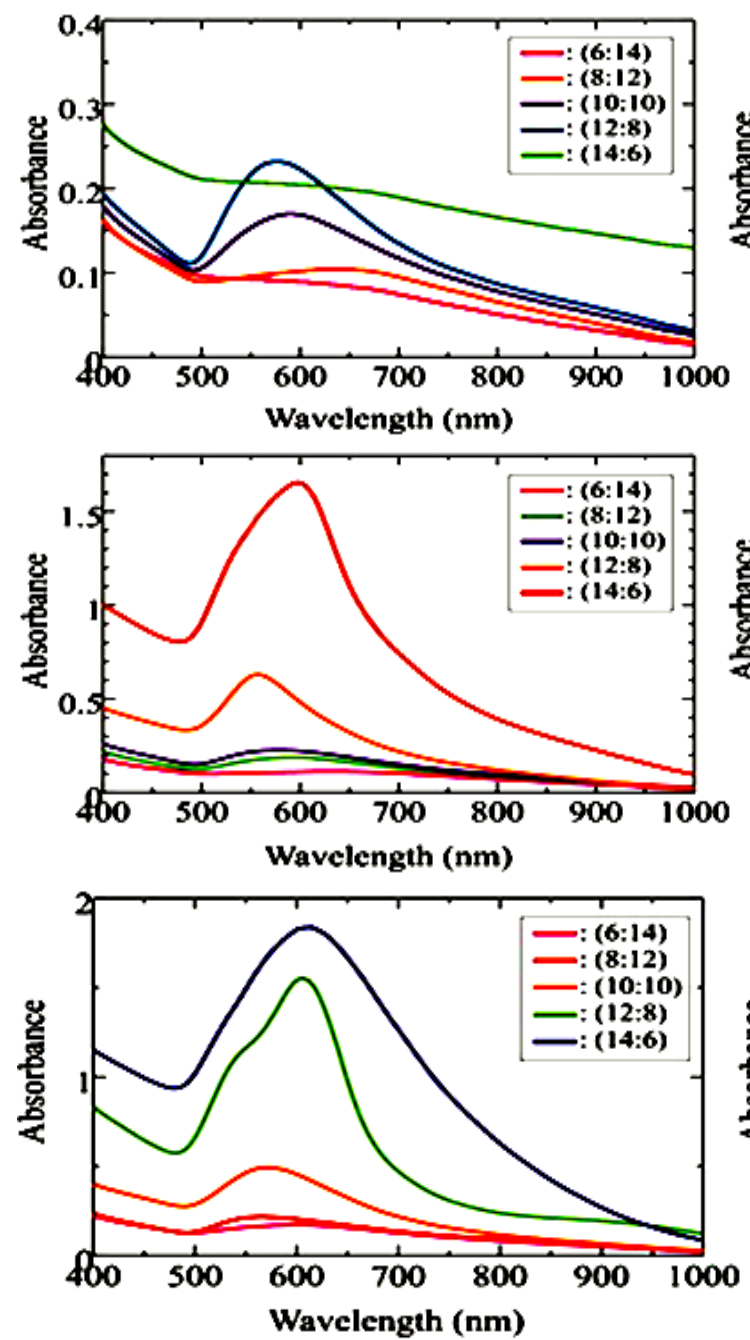

$0.6 \mathrm{mM}$, the formation of Au nanoparticles significantly increases, resulting well-shaped, high absorbancepeaks at volume ratio of $12: 8$ and $14: 6$, readily after preparation. Broader peaks were found at lower volume ratio, and at lowest volume ratio $(6: 14)$ the peak were not formed. The shape of the peaks were not alter significantly after 7 days, though the absorbance decreases to some extent. At higher metal precursor concentration $(0.8 \mathrm{mM})$, the stabilityof the nanoparticles were poorer, since at almost all volume ratio, except $12: 8$, the absorbance were drastically dropped. In this condition the initial formation rate of the nanoparticles were high, but those nanoparticles could not maintain their stability, probably due to intensive interaction between particles.
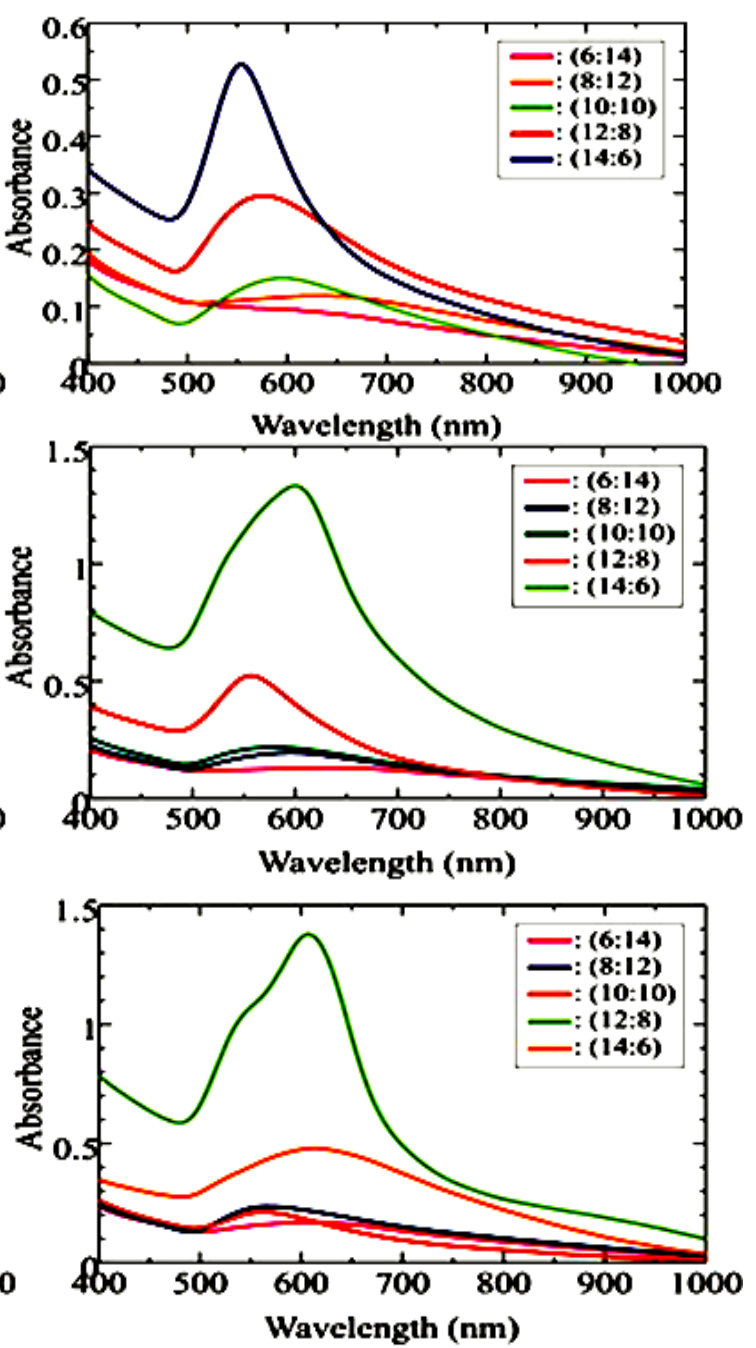

Fig. 6. SPR spectra of Au nanoparticles synthesized by wuluh starfruit extract at metal precursor concentration of $0.4 \mathrm{mM}$ (top), $0.6 \mathrm{mM}$ (middle) and $0.8 \mathrm{mM}$ (bottom), after preparation (left) and 7 days after preparation (right) 


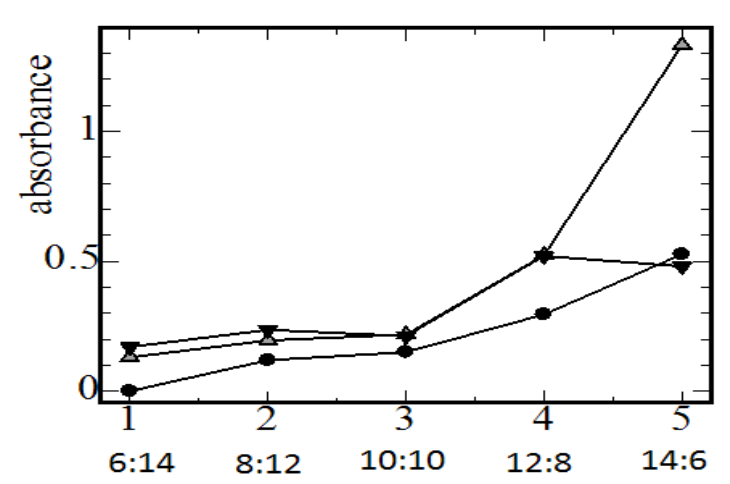

Fig. 7. Effect of volume ratio of metal precursor : Extract on the absorbance of Au nanoparticles (metal precursor concentration: $\bullet=0.4 \mathrm{mM}, \nabla=0.6 \mathrm{mM}, \Delta=0.8 \mathrm{mM}$ )

At high precursor concentrations, which is $0.8 \mathrm{mM}$, the shape of the particles is dominated by other than spherical, namely triangles (or triangular prisms), cubes and pentagons (or pentagon prisms). Likewise in the ratio of the volume of metal precursors: higher extracts, namely 12: 8, particle shapes tend to be triangles (or triangular prisms), cubes, pentagons (or pentagon prisms), parallelogram, trapezoidal and truncated triangles.

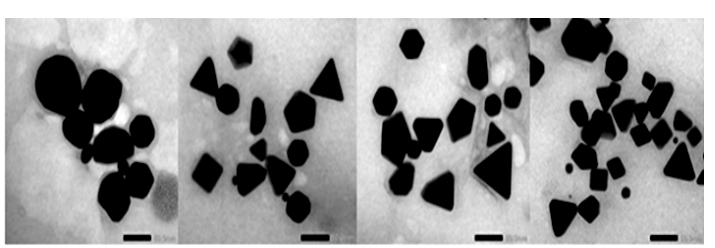

Fig. 8. TEM image of Au nanoparticles at metal precursor concentration of $0.4 \mathrm{mM}$ and $0.8 \mathrm{mM}$, and the ratio of metal precursors: extract $10: 10$ and $12: 8$, from left to right

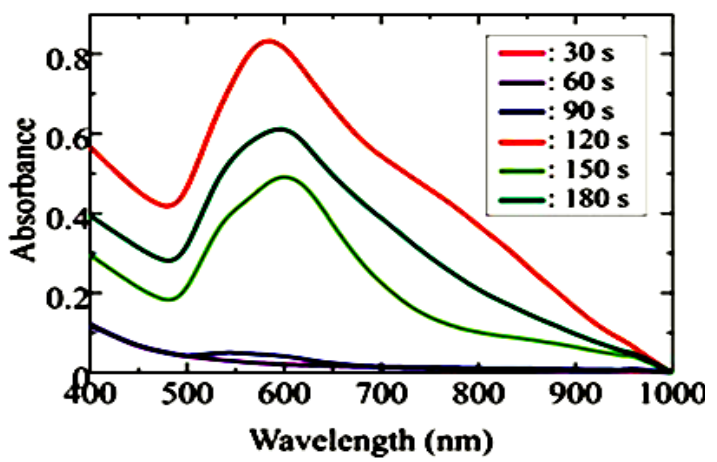

The shape of the sigmoidal curve shown in Fig. 8 indicates that the process of formation of $\mathrm{Au}$ nanoparticles is possible to run autocatalytically. In the first 30 sec. nanoparticle formation proceeded slowly, which was indicated by an insignificant increase in absorbance. For the next 30 to $90 \mathrm{sec}$. there is a high increase in absorbance. The increase in absorbance begins to decrease after the reaction runs over 90 sec. and even begins to decrease after $120 \mathrm{sec}$. but is followed by changes in the shape of the curve, which indicates changes in particle morphology. If the particle morphology has changed, then the absorbance change is irrelevant to compare.

\section{Antibacterial Test}

The testing of antibacterial activity of Escherichia coli and Bacillus was carried out on $0.8 \mathrm{mM}$ Au nanoparticles with various concentrations of both $10: 10 ; 12$ : 8 ; or 14: 6 . Escherichia coli represents Gram-negative microbes while Bacillus represents Gram-positive microbes, and test disc paper is immersed in $0.8 \mathrm{mM} \mathrm{Au}$ nanoparticle solution. This will cause the bioactive solution tested from $0.8 \mathrm{mM} \mathrm{Au}$ nanoparticles to be absorbed in disc paper. The same immersion method was also carried out on the antibacterial drug Amoxicillin with a concentration of $65 \mathrm{mg} / \mathrm{mL}$ as a positive control. The disc paper is then placed on the surface of solid media that has been sprinkled with microbes. After that, it was incubated at $37^{\circ} \mathrm{C}$ for $16-18$ hours. The inhibition zone produced was then compared with positive controls. The results of testing the antibacterial activity of Escherichia coli from $0.8 \mathrm{mM}$ Au nanoparticles are shown in Table 3 below.

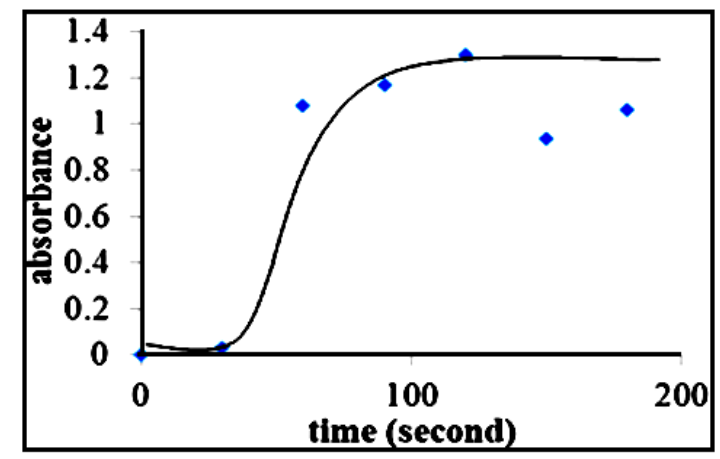

Fig. 9. SPR spectra of Au nanoparticles synthesized by wuluh starfruit extract at Au precursor concentration of $0.40 \mathrm{mM}$ at various irradiation time

Table 3: Test data for $0.8 \mathrm{mM}$ Au nanoparticle inhibition activity against Escherichia coli and Bacillus

\begin{tabular}{lcc}
\hline Reagen & $\begin{array}{r}\text { Inhibited Zone Size (mm) } \\
\text { Escherichia coli }\end{array}$ & Bacillus \\
\hline Standard amoxicillin & Positif (10) & Positif (10) \\
Nanoparticle Au 0,8 mM (10:10) & Positif (3) & Positif (5) \\
Nanoparticle Au 0,8 mM (12:8) & Positif (3) & Positif (1) \\
Nanoparticle Au 0,8 mM (14:6) & Positif (5) & Positif (5) \\
\hline
\end{tabular}

Table 3 shows that $0.8 \mathrm{mM}$ Au nanoparticles produce inhibitory zones in the antibacterial test, although the size of the inhibitory zone produced is relatively small compared to the standard amoxicillin. This shows that $0.8 \mathrm{mM}$ Au nanoparticles have low antibacterial activity against Escherichia coli and Bacillus. 


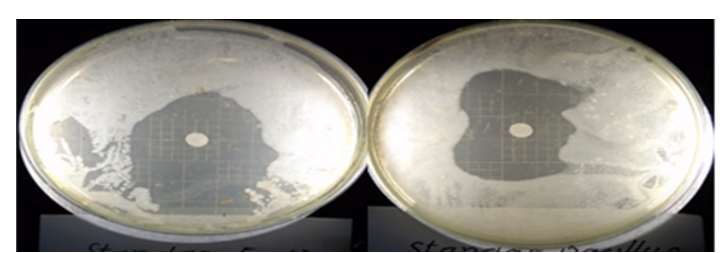

(a)

(b)

Fig. 10. The standard antibacterial test results of amoxicillin against Escherichia coli (a) and Bacillus bacteria (b)

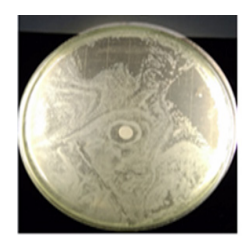

(a)

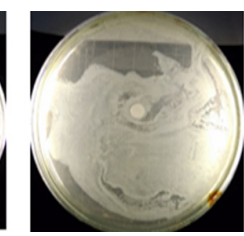

(b)

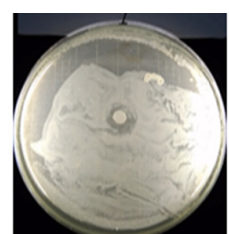

(c)
Fig. 11. Antibacterial test results of $E$. coli (a) $0.8 \mathrm{mM} \mathrm{Au}$ Nanoparticles 10:10 ; (b) $0.8 \mathrm{mM}$ Au Nanoparticles 12: 8 (c) $0.8 \mathrm{mM}$ Au nanoparticles 14: 6

In Fig. 11a clear zone is seen as an antibacterial inhibitory zone against Escherichia colibacteria from 0.8 $\mathrm{mM}$ Au nanoparticles with various variations between the Au metal precursors and an average of 3-5 mm of starfruit extract. This inhibition zone is smaller than the standard amoxicillin inhibition zone.

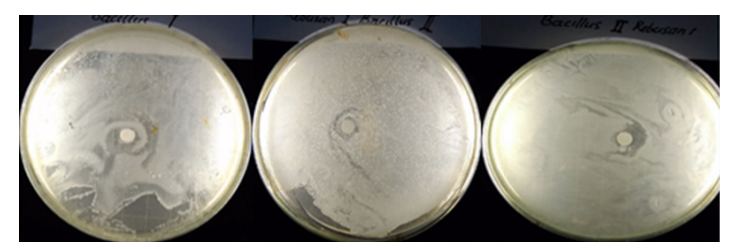

(a)

(b)

(c)

Fig. 12. Antibacterial test results of Bacillus (a) $0.8 \mathrm{mM}$ Au Nanoparticles 10:10 0.8 mM Au Nanoparticles 12: 8 (c) $0.8 \mathrm{mM}$ Au nanoparticles 14: 6
In Fig. 12a clear zone is seen as an antibacterial inhibitory zone against Bacillus bacteria from $0.8 \mathrm{mM}$ Au nanoparticles with various variations between the Au metal precursors and the average wuluh starfruit extract of $1-5 \mathrm{~mm}$. This inhibition zone is smaller than the standard amoxicillin inhibition zone.

\section{CONCLUSION}

Extract of wuluh starfruit was successfully played a role as reducing agent in the synthesis of $\mathrm{Au}$ nanoparticles. Both the phytochemicals and ascorbic acid contained in the extract may probably have large contribution to the efficiency of the synthesis. The morphology of these nanoparticles was greatly affected by both the Au precursor concentration and volume ratio of precursor : extract. The as-formed nanoparticles have medium antibacterial activity, toward Escherichia coli and Bacillus, in which the magnitude of antibacterial activity depends on the ratio of precursor : extract.

\section{ACKNOWLEDGEMENT}

AKA Bogor Polytechnic as a place to do research and assistance cost has been given with the Decree Director Polytechnic of AKA Bogor Number 72 / Poltek AKA / Kep / 5/ 2017 concerning the Establishment of a Research Team at the Polytechnic of AKA Bogor for the 2017 Budget.

\section{Conflict of interest}

The authors declare no conflicts of interest.

\section{REFERENCES}

1. Zakaria Z.A., Zaiton H.,Henie EFP, Matjais A.M, Engku Zainuddin ENH. In Vitro Antibacterial Activity of Averrhoa bilimbi L. Leaves and Fruits Extract. International Journal Tropical Med., 2007, 2, 96-100.

2. Ankamwar B. Biosynthesis of gold nanoparticles (green gold) using leaf extract ofterminalia catappa. E-Journal of Chemistry., 2010.

3. P. Ramesh,A. Rajendran, M. Meenakshi sindaram. Green Synthesis of Zinc Oxide Nanoparticles Using Flavour Extract Cassia Auriculata. Journal of Nanoscience and Nanotechnology., 2014, 2(1), 41-45.

4. Balaprasad A.; Minakshi Chaudhary; Murali Sastry. Gold nanotriangle biologically synthesized using tamarind leaf extract and potential application in vapor sensing synth react inorg metal. Org. Nanometal Chemistry., 2005.

5. Tripathy A., Ashok M. Raichur, N. Chandrasekaran, T.C. Prathna, Amitava Mukherjee. Process variable in biomimetic synthesis of silver nanoparticles by aqueous extract of Azadirachta indica (Neem) leaves. Journal Nanoparticles., 2010, 12, 237-246.

6. Das, K.R., Nayanmoni Gogoi, Punuri Jaya, Sekhar Babu, Pragya Sharma, Chandan Mahanta, Utpal Bora. The synthesis of gold nanoparticles using Amaranthus spinosus leaf extract and study of their optical properties. Journal of Advances in Materials Physics and Chemistry., 2012, 2, 275-281. 
7. Ashwani kumar Singh and O.N. Srivasta. One Step Green Synthesis of Gold Nanoparticles Using Black Cardamom and Effect of $\mathrm{pH}$ on Its Synthesis. Nanoscale Research Letter., 2015, DOI 10.1186/s11671-015-1055-4.

8. Alok Pani, Joong Hee Lee and Soon-II Yun. Autoclave mediated one-pot-one-minute synthesis of AgNPs and Au-Ag nanocomposite from Melia azedarach bark extract with antimicrobial activity against food pathogens. Chemistry Central Journal., 2016, 10, 15.

9. Foliatini and Nurdiani. Biosynthesis of Anisotropic Nanogold using Binahong (Anredera cordifolia) Leaves Extract as a Morphology Controlling Agent. International Journal of Chemistry Studies., 2017.

10. Selawa W., Max Revolta, John Runtuwene, dan Gayatri Citraningtyas. Kandungan flavonoid dan kapasitas antioksidan total ekstrak etanol belimbing wuluh (Anredera cordifolia). Pharmacon Jurnal IImiah Farmasi., 2013, 2 (1), ISSN 2302-2493.

11. Raghunandan, D., Bhat Ravishankar, Ganachari Sharanbasava, D. Bedre Mahesh, Vasanth Harsoor, Manjunath S. Yalagatti, M. Bhagawanraju, A. Venkataraman, Anticancer studies of noble metal nanoparticles synthesized using different plant extracts, Cancer Nano., 2011, 2, 57-65.

12. M. Jannathul Firdhouse and P. Lalitha. Flower Shaped Gold Nanoparticles Synthesized Using Kedrostis foetidissima and Their Antipoliferative Activity Against Bone Cancer Cell Lines. Int. J. Ind Chem., 2016, 7, 347-358.

13. Wijaya, L. Modifikasi Elektroda Karbon. FMIPA Universitas Indonesia., 2008.
14. Roxana-Diana Pasca, Aurora Mocanu, Simona-Codruta Cobzac, Ioan Petean, Ossi Horovitz, Maria Tomoaia-Cotisel. Biogenic Syntheses of Gold Nanoparticles using Plant Extracts. Particulate Science and Technology., 2014, 32(2), 131-137.

15. Zhang et al. Synergetic Antibacterial Effect of Silver Nanoparticles@Aloe vera Prepared via a Green Method. Nano Biomed Eng., 2010, 262-274.

16. Isaac, R. S. R., Sakthivel, G., \& Murthy, C. Green synthesis of gold and silver nanoparticles using averrhoa bilimbi fruit extract. Journal of Nanotechnology., 2013.

17. Preeti Dauthal and Mausumi Mukhopadhyay. Noble Metal Nanoparticles :Plant Mediated Synthesis, Mechanistic Aspects of Synthesis and Applications. Industrial and Engineering Chemistry Research., 2016.

18. Al Hassan Muhammad Al Hasan and Qomar Uddin Ahmed. Averrhoa bilimbi Linn : A Review of Its Ethnomedicine Uses, Pythochemistry and Pharmacology. Journal of Pharmacy \& BioAllied Sciences., 2016, 265-271.

19. Jiaguo Yu, Shengwei Liu, Chuan Li. Effect of PSS on Morphology and Optical Properties of ZnO. Journal of Colloid and Interface Science.,2008, 433-438.

20. Foliatini, Yoki Yulizar, Mas Ayu Elita Hafizah, Microwave-assisted Synthesis of Alginate Stabilized-Gold Nanoparticle, Makara J. Sci., 2014, 18(4), 111-118.

21. Bhattacharaya S. and Aasheesh Srivastava. Synthesis of gold nanoparticles stabilised by metal chelator and the controlled formationof close-packed aggregates by Them. Journal Indian Academy of Sciences., 2003. 